\title{
Kelola
}

\section{PENGEMBANGAN MODEL STRATEGI BERSAING BERBASIS THE NEW 7-S's SEKOLAH MENENGAH ATAS SWASTA DI KOTA SALATIGA}

\author{
Lowisye Leatomu \\ Alumni Program Pascasarjana Magister Manajemen Pendidikan \\ FKIP-Universitas Kristen Satya Wacana \\ wizhiejizrel@gmail.com; \\ Bambang Ismanto \\ Program Pascasarjana Magister Manajemen Pendidikan \\ FKIP-Universitas Kristen Satya Wacana \\ bambang.ismanto@staff.uksw.edu
}

\begin{abstract}
This study aimed to develop a competitive strategy development model based on the new 7S's in Satya Wacana Christian High School (SMA Lab) Salatiga. Tthis study is research and development, where the study was performed only at the fifth stage, the potential and problems, data collection, product design, design validation, and revision of the design. This research was conducted in Satya Wacana Christian High School (SMA Lab) Salatiga. Interviews were conducted with principal, vice principals curriculum, student section, public relations, teachers, administration of the employees, students and parents to know the framework of the new strategy 7-S's on Satya Wacana Christian High School. While study documentation was conducted to determine the profile of the school, student profile, the work program of principals, vice-principals work program of curriculum, student affairs, and public relations. After the data collected, then the data was reduced, summarized, categorized, synthesized and presented in narrative form and tables. Model-based development of competitive strategy the new 7-S's on Satya Wacana Christian High School consists of four rare developments, the formation of the team, defining the vision and mission, the analysis of the new 7-S's, and strategy development. Formulation of a strategy based on the analysis of the new 7-S's on Satya Wacana Christian High School consisted of three frameworks, namely Superior Stakeholder Satisfaction which includes the satisfaction of customers and workers, positioning program, and strategic cooperative.
\end{abstract}

Keywords: Model, competitive strategy, the strategy of the new 7-S's

\section{PENDAHULUAN}

Kebutuhan akan pendidikan yang lebih berkualitas membuat para pelanggan (calon siswa dan orang tua) lebih selektif dalam memilih jasa lembaga pendidikan yang akan digunakan. Keputusan konsumen untuk menggunakan jasa pendidikan sangat ditentukan bagaimana sekolah selaku penyedia jasa mampu memahami orientasi atau kecenderungan para konsumen dalam menggunakan jasa pendidikan. Pesatnya pertumbuhan lembaga- 
lembaga pendidikan disatu sisi memang sesuai dengan keinginan untuk meratakan kesempatan memperoleh pendidikan. Namun disisi lain menimbulkan persaingan antar lembaga pendidikan dalam memperoleh kepercayaan dari masyarakat (Indrawati, 2011: 26). Oleh karena itu, dalam menghadapi persaingan jasa pendidikan, maka penyelenggara pendidikan perlu mengelola sekolah seperti layaknya suatu bisnis dengan tidak meninggalkan aspek idiilnya (Remiasa, 2005: 14).

Kondisi real tingginya tingkat persaingan lembaga pendidikan di kota Salatiga, terlihat jelas dari banyaknya jumlah SMA dan SMK baik negri maupun swasta yang berada di kota Salatiga. Kota dengan luas wilayah $\pm 60 \mathrm{~km}^{2}$ ini, memiliki 11 sekolah mengengah atas yang terdiri dari 4 SMA Negeri dan 7 SMA swasta serta 18 sekolah menengah kejuruan yang terdiri dari 3 SMK negeri dan 15 SMK swasta. Dengan banyaknya jumlah SMA dan SMK yang ada di kota Salatiga, membuat setiap sekolah berusaha meningkatkan kualitasnya untuk mendapat kepercayaan dari masyarakat selaku pengguna jasa pendidikan. Hasil penelitian dari Sumarni (2011), menjelaskan bahwa, SMP Kristen Satya Wacana pada awalnya merupakan sekolah faforit di Salatiga dan mempunyai banyak prestasi, namun sekolah ini mengalami penurunan dalam beberapa tahun belakangan ini. Sementara, SMA Theresiana sebagai satusatunya SMA Katolik di Salatiga juga mengalami penurunan dalam kurun waktu 10 tahun terakhir (Panny, 2012). SMP Taman Dewasa sebagai salah satu sekolah terutama di kecamatan Ambarawa juga mengalami penurunan yaitu sejak tahun 2000 hingga saat ini. Sedangkan SD Kristen 1 Salatiga mengalami penurunan jumlah mengakibatkan satu kelas hanya berjumlah 9-11 anak. Selain itu kondisi lokasi sekolah yang sempit mengakibatkan proses belajar mengajar sering terganggu (Nevi, 2013).

Untuk menghadapi tingginya persaingan jasa pendidikan, Rahayu (2008: 64) menjelaskan satuan pendidikan dituntut untuk senantiasa merevitalisasi strateginya guna menjamin kesesuaian tuntutan lingkungan dan persaingan dengan kekuatan internal yang dimilikinya. Ketidakmampuan suatu satuan pendidikan dalam merespon peluang dan ancaman eksternal, akan mengakibatkan menurunnya daya saing atau terhambatnya pencapaian kinerja satuan pendidikan. Perencanaan pendidikan merupakan suatu proses penentuan tujuan, penciptaan lingkungan serta prasyarat untuk mencapai tujuan yang telah ditetapkan dengan cara yang paling efektif dan efisien dalam rangka pembentukan manusia yang memiliki kompetensi individual, sosial, dan profesional secara optimal (Tagela, 2013: 3). Tujuannya adalah agar jasa pendidikan yang diberikan dapat memenuhi kebutuhan dan harapan dari setiap penggunanya. Dimana, kemampuan administrator dalam melakukan scaning lingkungan eksternal, kompetitor lembaga lain, memperhitungkan kompetensi 
internal, dan menciptakan strategi yang mumpuni untuk memenangkan persaingan antar lembaga pendidikan adalah upaya yang harus dilakukan untuk merencanakan pendidikan yang berkualitas.

SMA Kristen Satya Wacana (SMA Lab) merupakan salah satu sekolah swasta yang berada di kota Saltiga. Sekolah yang merupakan laboratorium dari Universitas Kristen Satya Wacana ini, juga merupakan salah satu sekolah yang favorit mengikuti perkembangan tren dalam meningkatkan kualitas sekolah. Meskipun termasuk salah satu sekolah favorit, namun sebagian besar prestasi yang diraih oleh siswa SMA Lab adalah prestasi dalam bidang non akademik. Hasil wawancara pada tanggal 25 Januari 2015 dengan salah satu guru SMA Lab, menjelaskan bahwa sebagian besar prestasi yang diperoleh oleh siswa adalah prestasi dalam bidang nonakademik. Hal senada juga disampaikan oleh salah satu guru SMA Lab yang diwawancarai pada tanggal 14 Januari 2016. Salah satu dampak rendahnya potensi akademik siswa juga disebabkan karena input siswa SMA Lab secara umum memiliki kemampuan akademil pada level menegah ke bawah. Namun disisi lain, SMA Lab memiliki kapasitas yang sangat besar dalam meningkatkan prestasi siswa dalam bidang akademik maupun nonakademik. Oleh karena itu, pengembangan strategi yang tepat diharapkan dapat menjembatani permasalahan yang ada.

Mengapa SMA Kristen Satya Wacana (SMA Lab) perlu mengembangkan strategi bersaing? Hal ini disebabkan karena: 1) SMA Lab bukan satu-satunya sekolah yang berbasis agama kristen di kota Salatiga, 2) Saat ini semua sekolah baik swasta maupun negeri berlomba-lomba untuk meningkatkan kualitasnya dan terus berusaha memberikan layanan terbaik kepada masyarakat, 3) Biaya sekolah negeri lebih murah, 4) Mutu lulusan SMA negeri dan swasta relatif sama. Oleh karena itu, SMA Lab harus tampil dengan sesuatu yang unik, yaitu sesuatu yang hanya bisa didapatkan di SMA Lab. Dalam hal ini, SMA Lab perlu merancang strategi yang tepat dalam meningkatkan eksistensi sekolah. Strategi yang dapat menjawab kebutuhan pelanggan dan meningkatkan kinerja sekolah, strategi yang menjadi kekuatan dan memberikan peluang bagi sekolah dalam menghadapi kompetisi. Untuk menghadapi kondisi yang semakin dinamis (hypercompetitive) seperti sekarang ini, Richard A. D’Aveni (1994: 263), mengemukakan suatu ide dasar, bahwa perusahaan harus menekankan pada strategi yang memfokuskan pada pengembangan kompetensi inti (building core competency), pengetahuan dan keunikan(intangible asset), untuk menciptakan keunggulan. Kunci utama dari The New 7-S's adalah menggunaka inisiatif untuk merebut persaingan. 
Model pengembangan strategi bersaing berbasis the new 7-S's merupakan satu model deskriptif yang menerangkan atau mendeskripsikan langkah-langkah dalam pengembangan strategi bersaing bagi SMA Lab. Model pengembangan strategi ini, merupakan sebuah model yang dikembangkan untuk membantu sekolah mengembangkan strategi bersaingnya. Model ini dikembangkan berdasarkan kerangka kerja strategi the new 7-S's. Dimana untuk mengembangkan strategi bersaingnya, sekolah perlalu melakukan kajian atau analisis terkait kerangka kerja the new 7-S's untuk memperoleh gambaran tentang kondisi sekolah, sehingga strategi yang dikembangkan dapat menjawab masalah dan kebutuhan sekolah. Strategi bukanlah satu-satunya alat untuk meningkatkan eksistensi sebuah sekolah, tetapi untuk meningkatkan eksistensi dan dapat bersaing dengan institusi lainnya sekolah membutuhkan strategi yang tepat.

Yang Ying Ming, dkk. (2005:167), menyatakan bahwa model adalah suatu deskripsi naratif untuk menggambarkan prosedur atau langkah-langkah dalam mencapai satu tujuan khusus, dan langkah-langkah tersebut dapat dipergunakan untuk mengukur keberhasilan atau kegagalan dalam mencapai tujuan. Model merupakan suatu pola yang dibuat untuk menggambarkan atau menjelaskan desain suatu kerangka atau alur pikir yang digunakan sebagai pedoman dalam melakukan kegiatan untuk mencapai tujuan. Perumusan model itu sendiri menurut Widodo (2005), memiliki tujuan sebagai berikut: (i) memberikan deskripsi tentang kerja sistem untuk periode tertentu di mana di dalamnya secara implisit terdapat seperangkat aturan untuk melaksanakan perubahan, atau memprediksi cara sistem beroperasi di masa datang, (ii) memberikan deskripsi tentang fenomena tertentu menurut diferensiasi waktu atau memproduksi seperangkat aturan yang bernilai bagi keteraturan sebuah sistem, dan (iii) memproduksi model yang mempresentasikan data dan format ringkas dengan kompleksitas rendah. Pengembangan model merupakan upaya untuk mengaktifkan sumberdaya dan memperluas kesempatan dalam melakukan pembaruan menuju keadaan yang lebih baik.

Kotler (2001: 312), menyatakan strategi bersaing merupakan "strategi yang secara kuat menempatkan perusahaan terhadap pesaing dan yang memberi perusahaan keunggulan bersaing yang sekuat mungkin". Senada dengan Kotler, Hariadi (2005: 99) mengatakan strategi bersaing adalah langkah-langkah strategis yang terencana maupun tidak terencana untuk dapat memiliki keunggulan bersaing sehingga dapat menarik perhatian konsumen, memperkuat posisi dalam pasar, dan bertahan terhadap tekanan persaingan. Dari dua pendapat diatas, maka dapat disimpulkan bahwa strategi bersaing adalah upaya atau cara yang ditempuh oleh sebuah organisasi dalam memenangkan pasar sasarannya dengan cara 
Pengembangan Model Strategi Bersaing Berbasis The New 7-s's Sekolah Menengah Atas Swasta di Kota Salatiga | Lowisye Leatomu \& Bambang Ismanto

memberikan keunggulan-keunggulan dalam bersaing, menganalisis pesaing serta melaksanakan strategi bersaing yang efektif.

Tujuan Pelaksanaan Strategi Bersaing menurut Philip Kotler dan Gary Amstrong (2001: 230) yaitu: 1) membentuk suatu positioning yang tepat, 2) mempertahankan pelanggan yang setia, 3) mendapatkan pangsa pasar baru, 4) memaksimalkan penjualan, dan 5) menciptakan kinerja bisnis yang efektif. Strategi bersaing yang dipilih oleh suatu organisasi mengidentifikasi cara-cara dimana organisasi akan bersaing dalam pasaran produknya dan memberikan nilai yang terbaik bagi pelanggan. Strategi bersaing berusaha mengidentifikasi dan mengamankan segmen pasar yang paling menonjol dalam suatu arena pasaran produk. Oleh karena itu, strategi bersaing menentukan bagaimana suatu unit pendidikan harus berkompetisi dalam suatu segmen pasar untuk membangun keunggulan bersaingnya.

Untuk menghadapi kondisi yang semakin dinamis (hypercompetitive), Richard A. D’Aveni (1994: 263) mengajukan tujuh kunci keberhasilan perusahaan dalam menghadapi kondisi lingkungan yang hypercompetitive, yang dikenal dengan “The New 7-S's. Konsep the new 7-S's ini meliputi: (i) superior stakeholder satisfaction. (ii) strategic soothsaying. (iii) positioning for speed. (iv) positioning for surprise. positioning for surprise (v) shifting the rules of the game. (vi) signaling strategic intent. (vii) simultaneous and sequential strategic thrusts.

Rumusan masalah dalam penelitian ini adalah Bagaimana model pengembangan strategi bersaing berbasis The New 7-S's pada SMA Kristen Satya Wacana (SMA Lab)?. Berdasarkan rumusan masalah tersebut, maka tujuan penelitian ini adalah Untuk mengembangkan model pengembangan strategi bersaing berbasis The New 7-S's pada SMA Kristen Satya Wacana (SMA Lab)?. Hasil penelitian ini bermanfaat untuk menambah referensi pengetahuan dalam bidang manajemen pendidikan, khususnya mengenai strategi bersaing bagi sekolah. Disamping itu hasil penelitian ini juga diharapkan dapat menjadi referensi untuk penelitian selanjutnya. Dan juga hasil penelitian ini dapat digunakan sebagai panduan bagi SMA Kristen Satya Wacana (SMA Lab) untuk mengembangkan strategi bersaingnya.

Kerangka pikir dalam penelitian ini diawali dengan tingginya tingkat persaingan di dalam dunia pendidikan. Dimana semua sekolah berusaha untuk meningkatkan strategi yang digunakan dalam memperoleh siswa. Dewasa ini, biaya pendidikan bukan lagi merupakan sesuatu yang menghalangi pelanggan untuk menggunakan jasa pendidikan yang ditawarkan, ketika mereka merasa bahwa jasa yang ditawarkan adalah sesuatu yang benar-benar mereka butuhkan. Besar kecilnya biaya bukan lagi menjadi kendala, ketika kebutuhan akan jasa 
pendidikan semakin meningkat, melainkan nilai, kualitas, tujuan, visi dan layanan yang baik merupakan tolak ukur dalam menggunakan barang dan jasa. Richard D'Aveni menjelaskan, dalam menghadapi kondisi yang demikian, pengembangan kompetensi inti dan membuat strategi-strategi yang mencengangkan merupakan hal-hal yang harus dilakukan oleh manajemen dalam meningkatkan daya saing untuk memperoleh keuntungan. Hasil analisis terhadap kerangka strategi the new 7-S's, nantinya akan menghasilkan strategi bersaing yang dapat menjadi pedoman bagi SMA Kristen Satya Wacana (SMA Lab) Salatiga untuk meningkatkan kualitas layanannya.

\section{Gambar 1. Kerangka Berpikir}

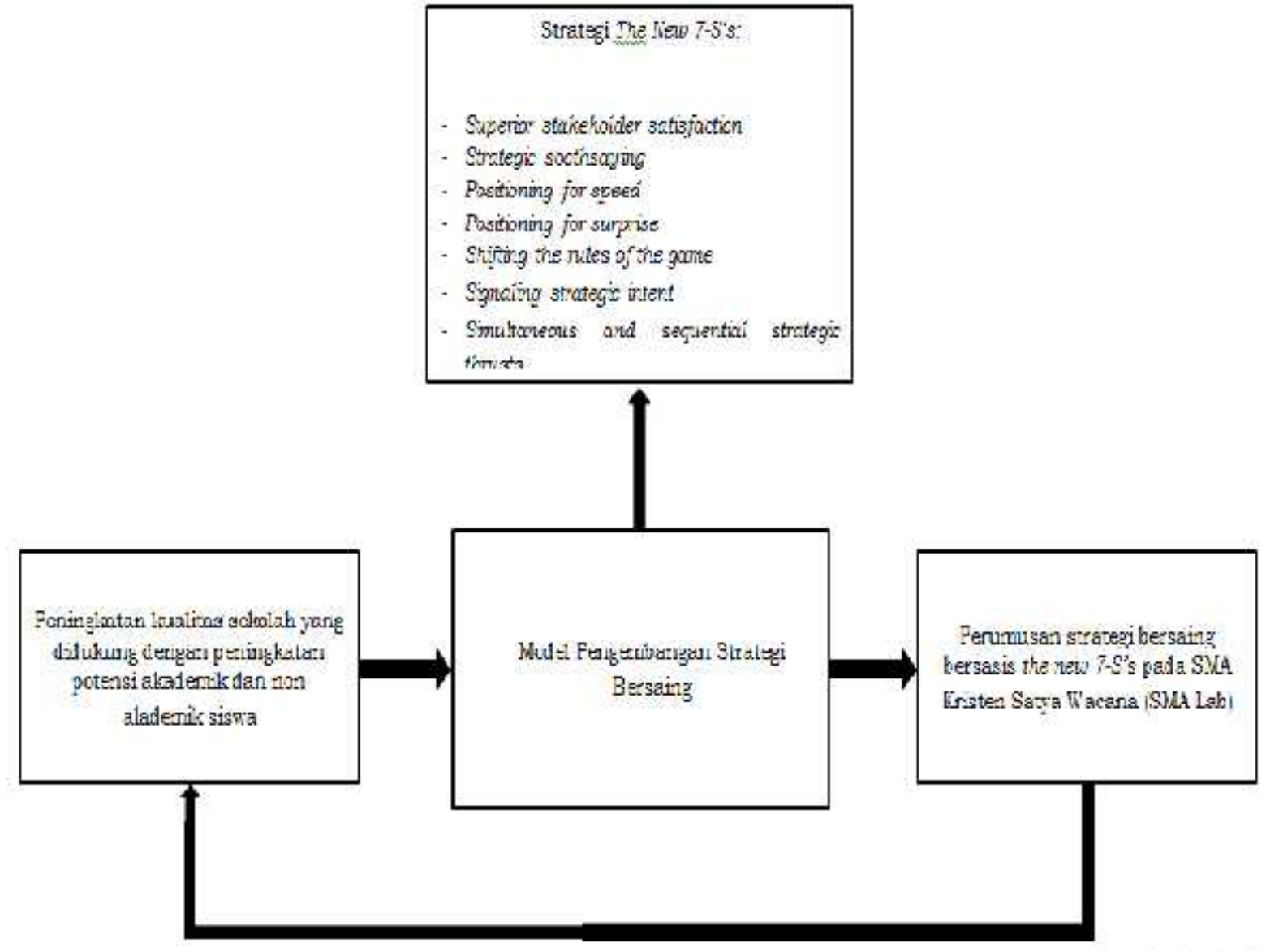

\section{METODE PENELITIAN}

Jenis penelitian yang digunakan dalam penelitian ini adalah Research and Development (Sugiyono, 2010: 407). Penelitian ini dilakukan di SMA Kristen Satya Wacana (SMA Lab) Salatiga, sejak 14 Januari 20164-3 Maret 2016. Variabel dalam penelitian ini adalah tujuh kerangka strategi the new 7-S's, yaitu (i) superior stakeholder satisfaction, (ii) strategic soothsaying, (iii) positioning for speed, (iv) positioning for surprise, (v) shifting the 
Pengembangan Model Strategi Bersaing Berbasis The New 7-s's Sekolah Menengah Atas Swasta di Kota Salatiga | Lowisye Leatomu \& Bambang Ismanto

rules of the game, (vi) signaling strategic intent, dan (vii) simultaneous and sequential strategic thrusts. Sementara jenis data dalam penelitian ini adalah data kualitatif yang diperoleh dari wawancara dan studi dokumentasi. Selanjutnya data yang diperoleh kemudian direduksi, dirangkum, dikategorikan, disintesiskan, dan kemudian disajikan dalam bentuk narasi dan tabel.

\section{HASIL PENELITIAN}

Berdasarkan prosedur penelitian dan pengembangan, maka proses dalampenelitian ini meliputi:

Potensi dan Masalah. Berdasarkan studi pendahuluan yang telah dilakukan pada Januari 2015, ditemukan bahwa penyebab rendahnya input siswa pada SMA Lab adalah masalah rendahnya potensi akademik siswa. Sementara potensi yang dimiliki oleh SMA Kristen Satya Wacana adalah kegiatan ekstrakurikuler, sarana dan prasarana penunjang proses pembelajaran yang memadai, program internasional, dan tenaga pendidik yang berkualifikasi. Berdasarkan potensi dan masalah tersebut, maka dilakukan studi literatur terhadap hasil penelitian ilmiah untuk memberikan gambaran bahwa rendahnya potensi akademik siswa merupakan salah satu indikator rendahnya daya saing sekolah. Hasil penelitian Belfied dan Levin (2002), dengan judul the effects of competition on educational outcomes: a review of US evidence, menjelaskan bahwa hasil dari 25 penelitian tentang pengaruh hasil akademik terhadap daya saing, menunjukan bahwa lebih dari satu per tiga mengatakan ada korelasi yang signifikan meningkatnya persaingan dengan tingginya prestasi sekolah.

Pengumpulan Data. Pengumpulan data dilakukan dengan wawancara, studi dokumentasi, dan observasi. Data yang dikumpulkan terkait dengan kerangka kerja strategi the new 7-S's pada SMA Lab. (1) superior stakeholdersatisfaction, menjelaskan kepuasan layanan yang diterima oleh customers dan workers serta harapan dan keinginan customers dan workers.(2) strategi soothsaying, merupakan usaha yang dilakukan sekolah untuk memenuhi kebutuhan pendidikan customers. (3) positioning for speed, merupakan usaha yang dilakukan sma lab sebagai pelopor pelaksanaan kegiatan. (4) positioning for surprise, adalah usaha sma lab untuk mencengangkan pesaing. (5) shifting the rules of the game, merupakan pembaharuan yang dilakukan oleh sma lab. (6) signaling strategic intent, merupakan tindakan sebagai signal untuk bersaing. (7) simultaneous and sequential strategic thrusts, strategi yang digunakan untuk meningkatkan kualitas sekolah, membangun jalam membangun kemitraan

Model Pengembangan strategi bersaing berbasis the new 7-S's, terdiri dari empat langkah pengembangan: 
1. Pembentukan tim

Dalam struktur tim, kepala sekolah berperan sebagai leader, ketua tim berperan sebagai penanggung jawab pengembangan dan pelaksanaan strategi yang bertanggung jawab langsung kepada kepala sekolah, dan tim peneliti dan pengembangan yang menganalisis the new 7-S's dan mengembangkan strategi.

\section{Gambar 2. Struktur Tim Pengembangan Strategi}

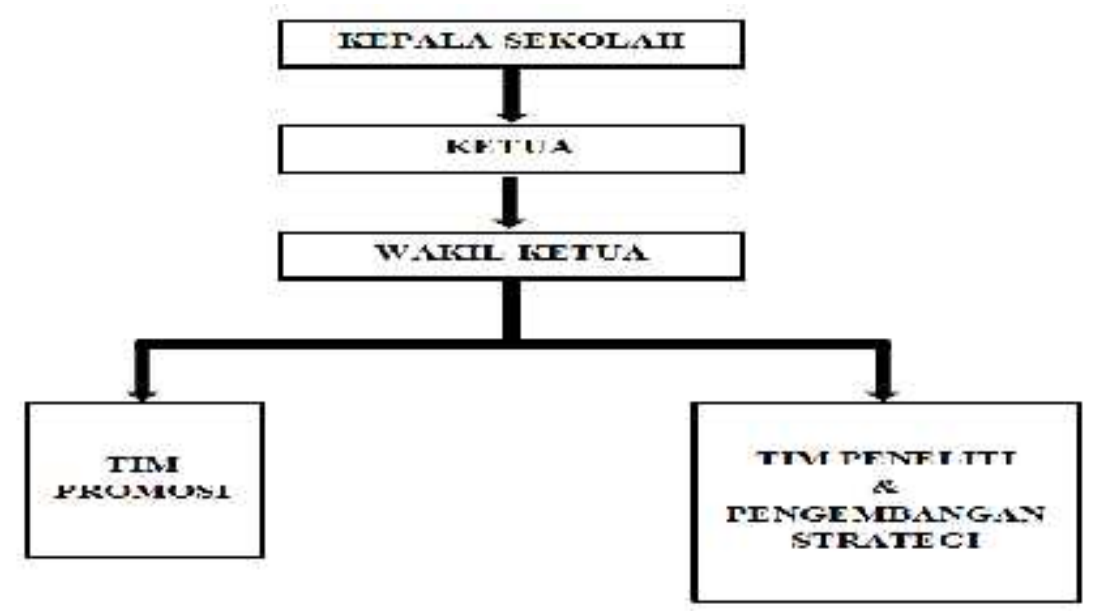

Hasil riset pada SMA Kristen Satya Wacana (SMA Lab), menunjukan bahwa SMA Lab memiliki tim dalam menyusun strateginya, tetapi dalam hal ini tim yang dimaksud adalah tim promosi yang bertugas untuk memasarkan jasa pendidikan dan memprospek para pelanggan untuk menggunakan jasa pendidikan di SMA Lab. Tim ini hanya menyusun strategi-strategi apa yang harus dilakukan dalam memasarkan jasa pendidikan dan memprospek siswa, bukan untuk menyusun strategi bersaing untuk meningkatkan kualitas sekolah.

\section{Menentukan Visi dan Misi}

Terlepas dari visi dan misi sekolah, pada tahap ini, pihak manajemen dapat menentukan visi dan misi yang menjadi sasaran khusus dari SMA Lab dalam mencapai tujuannya.

Visi SMA Kristen satya Wacana adalah "kembali ke masa pencerahan, bersaing dalam prestasi, mewujudkan kesejahteraan lahir batin untuk seluruh keluarga besar SMA Lab. Misi SMA Kristen Satya Wacanan (SMA Lab) adalah: 1) mengembalikan keadaan SMA Lab ke masa pencerahan, 2) mengembangkan potensi siswa di bidang akademis dan non akademis (olahraga, seni, dan karya tulis), 3) mengembangkan jiwa seni dan budaya 
Pengembangan Model Strategi Bersaing Berbasis The New 7-s's Sekolah Menengah Atas Swasta di Kota Salatiga | Lowisye Leatomu \& Bambang Ismanto

serta kesetiakawanan, 4) meningkatkan kesejahteraan seluruh warga SMA Lab (retreat, studi banding, menciptakan suasana kerja yang nyaman, meningkatkan status guru dan pegawai, 5) menumbuhkembangkan semangat rasa cinta tanah air dan bangsa, 6) memupuk rasa cinta akan kebersihan, keindahan, keamanan, kesejahteraan dan kekeluargaan.

\section{Analisis the new 7-S's}

(1) superior stakeholdersatisfaction, kepuasan dari sisi customers, kepuasan yang diterima: sarana dan prasarana, program internasional, keamanan dan kenyamanan lingkungan sekolah, pembinaan karakter dan kerohanian, pelayanan administrasi, layanan BK, kegiatan ekstrakurikuler, dan proses penerimaan siswa baru. Harapan dari customers: peningkatan kedisiplinan siswa, peningkatan komunikasi antara pihak sekolah dengan orang tua, peningkatan perhatian terhadap peraturan pemerintah tentang ketentuan siswa pindahan, melibatkan orang tua untuk meningkatkan kualitas siswa, peningkatan proses belajar siswa, peningkatan mutu dan karakter guru, inovasi program atau layanan, penyesuaian model pembelajaran dengan kondisi siswa, peningkatan kreatifitas guru, peningkatan fasilitas laboratorium, peningkatan prestasi siswa, dan peningkatan motivasi siswa. Dari sisi workers, kepuasa yang diterima adalah peningkatan koprofesionalisme guru dan kesejahteraan guru dan pegawai. Sementara harapan dari workers adalah: penyediaan fasilitas untuk meningkatkan kualitas pegawai, peningkatan perhatian yayasan kepada SMA Lab, peningkatan kesiapan tim promosi, lebih jelas pembagian waktu efektif di kelas, peningkatan kinerja guru, memperjelas aturan tertulis, peningkatan karakter dan kedisiplinan siswa, dan peningkatan kepedulian terhadap siswa. (2) strategi soothsaying, melalui penggunaan kurikulum 2013, kegiatan ekstrakurikuler yang variatif, sarpras yang memadai, dan wisuda bagi kelas XII. (3) positioning for speed, melalui sistem mooving class dan kegiatan live in. (4) positioning for surprise, melalui program internasiona, program reinforcement, dan olimpiade dengan korea. (5) shifting the rules of the game, pembaharuan sistem mooving class dengan menambahkan loker, AC, dan LCD proyektor, dan pembaharuan kegiatan live in dengan kegiatan pelopor studi ke Bali dan tour ke Korea. (6) signaling strategic intent, melalui student profile dan pemberian kualitas terbaik dengan biaya rendah. (7) simultaneous and sequential strategic thrusts, membangun kemitraan dengan SMP-SMP yang memiliki antusias tinggi terhadap SMA Lab, kerjasama dengan Korea, Australia, dan Jepang, dan membangun kemitraan dengan instansi terkait. 


\section{Pengembangan strategi}

Untuk menjawab harapan dari customers dan workers, maka dikembangka strategi berikut yang disesuaikan dengan potensi yang dimiliki oleh SMA Kristen Satya Wacana. Untuk menjawab harapan dari para customers, maka ada beberapa hal yang harus dilakukan, antara lain: 1) SMA Lab perlu memperjelas aturan tertulis tentang kewajiban yang harus dilakukan oleh setiap siswa saat berada dalam lingkungan sekolah, 2) pihak SMA Lab dapat memberikan surat pemberitahuan kepada orang tua melalui siswa, serta rencana kegiatan yang akan dilakukan oleh siswa. Sehingga orang tua bisa mengetahui hal-hal apa saja yang akan dilakukan oleh siswa, 3) SMA Lab dapat melaksanakan kegiatan matrikulasi untuk mempersiapkan siswa sebelum mengikuti pendidikan di SMA Lab. Dalam hal ini, sekolah membantu siswa untuk memenuhi persyaratan yang dibutuhkan untuk menjadi siswa di SMA Lab, 4) pihak SMA Lab bisa membuat peraturan tertulis yang akan memberikan sanksi bagi siswa yang melanggar aturan kebersihan serta menggunakan jasa petugas kebersihan sekolah untuk membersihkan toilet, 5) SMA Lab juga bisa memberikan kesempatan kepada orang tua dengan cara memberikan lembaran penilaian kinerja disetiap akhir semester untuk mengukur kinerja baik dari administrasi, keuangan, dll serta orang tua juga dapat memberikan masukan berupa saran-saran untuk mengembangka kualitas siswa meningkatkan kepedulian terhadap siswa saat di dalam kelas, dengan cara tidak membatasi siswa untuk bertanya ketika materi tidak dipahami, 6) pihak SMA Lab bisa melakukan pengembangan pembinaan dan pengembangan kompetensi akademik, kepribadian, sosial dan profesional guru dengan jalan mengikutsertakan para guru pada kegiatan workshop ataupun seminar-seminar terkait peningkatan kompetensi dan karakter guru maupun melakukan kerjasama dengan pihak UKSW untuk memberikan pelatihan tentang pengembangan kompetensi dan karakter guru, dan guru juga dapat memberikan lembaran penilaian kepada siswa untuk mengukut kegiatan pembelajaran yang telah dilakukan dan dengan feedback dari siswa ini, dapat menjadi pedoman bagi guru untuk memperbaiki kinerjanya dalam mengajar, 8) guru dituntut untuk lebih intens dalam proses pembelajaran dan ketika ada siswa yang tidak lulus, guru bisa melakukan kegiatan remedial untuk memperbaiki nilai siswa, sehingga tidak ada kecemburuan diantara para siswa terkait nilai yang didongkrak, 9) penyediaan buku terkait dengan model-model atau metode pembelajaran yang digunakan serta bekerjasama dengan UKSW untuk mendatangkan pakar atau ahli dalam bidang pendidikan untuk menjelaskan atau melatih para guru dalam menggunakan metode yang 
Pengembangan Model Strategi Bersaing Berbasis The New 7-s's Sekolah Menengah Atas Swasta di Kota Salatiga | Lowisye Leatomu \& Bambang Ismanto

sesuai dengan keadaan siswa, dan 10) selain dengan menggunakan metode atau model pembelajaran yang tepat guru juga bisa membuat kegiatan pembelajaran seperti sebuah permainan yang bisa disesuaikan dengan materi pelajaran sehingga akan lebih meningkatkan semangat siswa untuk belajar.

Sementara untuk memenuhi harapan dari workers, maka berikut merupakan kegiatan yang dapat dilakukan oleh sekolah: 1) SMA Lab bisa memfasilitasi dengan cara memberikan kesempatan kepada para pegawai untuk mengikuti workshop atau seminarseminar terkait peningkatan keprofesionalisme mereka atau melakukan kerjasama dengan UKSW untuk melakukan pembinaan dan pengembangan karier pegawai. 2) SMA Lab dapat meningkatkan komunikasi dengan pihak yayasan sehingga SMA Lab tidak ketinggalan dalam berbagai informasi yang diberikan ataupun kegiatan yang dilakukan, 3) tim promosi melakukan evaluasi terkait dengan usaha yang telah dilakukan untuk memprospek calon siswa, dan juga harus memiliki rencana cadangan ketika kondisi yang dihadapi berbeda dengan rencana yang telah disiapkan, membuat perencanaan pemasaran berdasarkan hasil analisis harapan customers, dan pihak sekolah bisa memfasilitasi tim promosi untuk mengikuti seminar tentang cara melakukan promosi jasa pendidikan untuk meningkatkan pengetahuan dan kemampuan tim dalam melakukan promosi, dan pihak sekolah bisa menyediakan buku-buku terkait dengan pemasaran jasa pendidikan, dan 4) bagian kurikulum agar lebih selektif dalam menentukan waktu efektif di kelas dengan kegiatan ekstrakurikuler maupun kegiatan pengembangan potensi siswa lainnya, sehingga guru tidak kesulitan dalam menyelesaikan materi pelajaran yang akan diberikan.

\section{PEMBAHASAN}

Berdasarkan hasil analisis terkait dengan kerangka kerja the new 7-S's pada SMA Kristen Satya Wacana, maka formulasi strategi bersaing berbasis the new 7-S's pada SMA Kristen Satya Wacana merupakan gambaran dari kondisi pelayanan yang diberikan oleh SMA Kristen Satya Wacana saat ini kepada konsumennya. Tabel formulasi strategi dapat dilihat pada lampiran 1.

Superior stakeholder satisfaction merupakan strategi yang menjelaskan tingkat kepuasan yang diterima oleh customers, dalam hal ini siswa dan orang tua serta workers dalam hal ini guru dan pegawai. Berikut merupakan kepuasan yang dirasakan oleh customers, sarana dan prasarana, program internasional, keamanan dan kenyamanan lingkungan sekolah, pembinaan karakter dan kerohanian siswa, pelayanan administrasi, BK, ekstrakurikuler, dan 
penerimaan siswa baru. Sementara dari sisi workers, peningkatan kompetensi guru dan kesejahteraan guru dan pegawai.

Positioning program merupakan strategi yang menjelaskan potensi yang dimiliki dan layanan yang diberikan oleh SMA Lab kepada konsumennya. Produk merupakan hal yang paling mendasar yang menjadi pertimbangan konsumen dalam menggunakan jasa pendidikan yang diberikan oleh SMA Lab, dimana diferensiasi produk akan memberikan dampak terhadap masa depan konsumen dan memberikan citra kepada SMA Lab. Produk yang ditawarkan oleh SMA Lab kepada konsumen, berupa penggunaan kurikulum 2013, kegiatan ekstrakurikuler, students profile, dan program internasional. Price merupakan besarnya harga yang harus dibayar oleh konsumen untuk menggunakan jasa pendidikan pada SMA Lab. Harga merupakan elemen yang berjalan sejajar dengan mutu atau kualitas produk, dimana konsumen akan berani membayar lebih jika produk yang ditawarkan berkualitas. Untuk dapat menikmati pendidikan di SMA Lab, maka calon siswa harus membayar, biaya pendaftaran, DP3, USP, SPP, dan uang seragam. Place merupakan letak atau tempat dimana SMA Lab berada. Meskipun SMA Lab tidak berada pada posisi yang strategis, karena tidak berada pada pusat kota yang dapat dijangkau dengan kendaraan umum, namun dengan keberadaannya yang bersamaan dengan UKSW hal ini menjadi nilai tambah bagi SMA Lab karena mudah untuk dijangkau oleh konsumen. Promotion merupakan upaya yang dilakukan oleh SMA Lab dalam memasarkan jasa pendidikannya. Untuk memasarkan jasa pendidikannya, SMA Lab menggunakan brosur, website sekolah, tim promosi, dan tutor sebaya (prospek senior-junior). Physical evidence, merupakan tampilan bangunan atau bentuk fisik dari SMA Lab. Selain kualitas yang baik, tampilan bangunan juga memberikan kontribusi bagi konsumen untuk menggunakan jasa pendidikan yang ditawarkan. Physical evidence juga merupakan sarana yang digunakan oleh SMA Lab untuk melengkapi dan membantu meningkatkan kualitas siswa yang akan berdampak pada peningkatan kualitas sekolah. Berikut merupakan bentuk fisik atau kondisi bangunan yang dimiliki oleh SMA Lab: laboratorium (biologi, fisika, dan kimia), lab komputer, ruang kelas, ruang kepala sekolah, ruang guru, ruang tenaga administrasi, ruang bk, ruang OSIS, gedung olah raga, cafetaria, teater, perpustakaan, UKS (putra/putri), toilet, Atm, klinik, Dll. People, merupakan sumber daya manusia (SDM) pada SMA Lab. SMA Lab memiliki tenaga pengajar dan tenaga administrasi yang berkualifikasi. Untuk lebih jelasnya dapat dilihat pada lampiran 2 dan struktur organisasi pada lampiran 3. Process, merupakan rangkaian kegiatan yang dialami atau dijalani siswa saat mengikuti pendidikan di SMA Kristen Satya Wacana. Ketika siswa menjalani pendidikan di SMA Lab, maka ada berbagai macam terkait pengembangan potensi baik akademik maupun non 
akademik siswa. Berikut merupakan proses yang harus dijalani siswa saat mengikuti pendidikan di SMA Lab: proses pembelajaran dengan sistem moving class, penjurusan sejak kelas X, program reinforcement, dan kegiatan wisuda bagi kelas XII.

Cooperative strategi merupakan strategi yang menjelaskan upaya yang dilakukan untuk meningkatkan kualitas SMA Lab dengan jalan membangun kerjasama dengan berbagai instansi. Kerjasama yang dibangun selain untuk mendapat dukungan dari berbagai pihak juga sebagai upaya untuk memberikan kesempatan atau pengalam belajar yang berbeda kepada siswa. Berikut merupakan bentuk kerjasama yang dijalankan oleh SMA Lab: membangun kemitraan dengan SMP-SMP yang mempunyai antusias tinggi terhadap SMA Lab, kerjasama dengan negara lain seperti Korea, Australia dan Jepang untuk pertukaran pelajar setiap tahun, dan membangun kemitraan dengan instansi lain terkait pengembangan kualitas pendidikan di SMA Lab.

\section{SIMPULAN DAN SARAN}

\section{Simpulan}

Berdasarkan hasil analisis dan pembahasan, maka kesimpulan yang dihasilkan adalah untuk mengembangkan strategi bersaing berdasarkan model pengembangan strategi bersaing berbasis the new 7-S's, maka ada empat langkah yang harus dilakukan oleh SMA Lab, yaitu: 1) Pembentukan tim, 2) menentukan visi dan misi, 3) analisis the new 7-S's, dan 4) pengembangan strategi bersaing.

\section{Saran}

Berdasarkan hasil penelitian, maka saran yang dihasilkan adalah sebagai adalah (1) pihak Yayasan perlu meningkatkan komunikasi dengan pihak SMA Lab, sehingga para pegawai SMA Lab tidak merasa diabaikan dan terlupakan untuk setiap informasi atau kegiatan yang dilaksanakan oleh yayasan. (2) sebagai seorang manajer dapat mempertimbangkan untuk melakukan pembaharuan-pembaharuan terhadap strategi-strategi yang selama ini telah dilakukan dan mempertimbangkan utuk melakukan pembaharuan terhadap tujuan dari SMA Kristen Satya Wacana, mengingat tujuan SMA Lab merujuk pada undang-undang No 20 tahun 2003 tentang sistem pendidikan nasional, dimana tujuan ini tidak lagi relevan dengan standar nasional pendidikan No 13 tahun 2015. (3) untuk guru, diharapkan guru dapat lebih peduli dengan siswa saat pembelajaran dengan cara meningkatkan semangat dan motivasi serta jiwa kompetisi agar siswa terpacu untuk belajar, dan dalam penggunaan metode atau model pembelajaran agar disesuaikan dengan 
kemampuan siswa. Untuk karyawan untuk meningkatkan pelayanan bagi siswa dan orang tua, sehingga tidak terjadi kesalahpahaman dan kesalahan dalam hal akses informasi.

\section{DAFTAR PUSTAKA}

Aniek Indrawati. Pengaruh Kualitas Layanan Lembaga Pendidikan terhadap Kepuasan Konsumen. JURNAL EKONOMI BISNIS, TH. 16, NO. 1, MARET 2011. (http://fe.um.ac.id/wp-content/uploads/2009/10/4-Aniek-Indrawati.pdf)

D’Aveni. R. A. 1994. Hypercompetition: Managing the dynamics of strategic maneuvering. The Free Press, Macmillan Inc, New York

Joko Widodo. 2005. Perencanaan Pendidikan di Sekolah Kejuruan; Disertasi. Bandung: PPS IKIP Bandung.

Marcus Remiasa. Perencanaan Strategis Pemasaran untuk Menciptakan Sustainable Competitive Advantage. JURNAL MANAJEMEN PERHOTELAN, VOL. 1, NO. 1, MARET 2005: 14-23. (file:///C:/Users/USER/Downloads/16234-16232-1-PB.pdf)

Nanik Sumarni. 2011. Strategi Peningkatan Mutu Sekolah Berdasarkan Analisis SWOT Pada SMA Kristen Satya Wacana Salatiga. Tesis.UKSW.

Olivia Nevi Noya. 2013. Strategi Bersaing Sekolah Menengah Atas Kristen 1 Salatiga. (http://repository.uksw.edu/bitstream/123456789/5153/2/T2_942012004_BAB\%20I.pdf)

Panny Imanuel Dae. 2012. Pelaksanaan Bauran Pemasaran Sekolah Menengah Atas Theresiana Salatiga. Tesis.UKSW.

Philip Kotler. 2001. Manajemen Pemasaran: Analisis, Perencanaan, Implementasi, dan Kontrol. Jakarta : PT. Prehallindo

\& Gary Amstrong. 2001. Prinsip-prinsip Pemasaran. Edisi Kedelapan, Jilid 2. Jakarta: Erlangga

Rahayu, A. 2008. Strategi Pemasaran Model untuk Keunggulan. Bandung: Rizqi Press

Sugiyono. 2010. Metode Penelitian Pendidikan: Pendekatan Kuantitatif, Kualitatif, dan $R \& D$. Bandung: Alfabeta

Yang, Ming-Ying, Manlai You, Fei-Chuan Chen. 2005. Competencies and Qualification for Industrial Design Jobs: Inplications for Design Practice, Education, and Student Career Guidance. Elsevier Ltd. 


\section{Lampiran 1}

Tabel Formulasi Strategi Bersaing Berbasis The New 7-S' Pada SMA Kristen Satya Wacana

\begin{tabular}{|c|c|c|}
\hline No & The New 7-S's & Strategi \\
\hline 1 & $\begin{array}{l}\text { Superior Stakeholder } \\
\text { Satisfaction }\end{array}$ & $\begin{array}{l}\text { Customers (siswa dan orang tua): } \\
\text { - Sarana dan prasarana penunjang proses pembelajaran } \\
\text { - Program internasional } \\
\text { - Lingkungan sekolah yang aman dan nyaman } \\
\text { - Pembinaan karakter dan kerohanian siswa } \\
\text { - Pelayanan administrasi dan keuangan (sebagian) } \\
\text { - Pelayanan bimbingan dan konseling } \\
\text { - Kegiatan ekstrakurikuler } \\
\text { - Proses penerimaan siswa yang mudah } \\
\text { Workers (guru dan pegawai): } \\
\text { - Peningkatan kompetensi profesional guru } \\
\text { - Kesejahteraan dalam hal finansial (gaji dan tunjangan) } \\
\text { guru dan pegawai }\end{array}$ \\
\hline 2 & Positioning program & $\begin{array}{l}\text { Product: } \\
\text { - Kurikulum } 2013 \\
\text { - Ekstrakurikuler } \\
\text { - Students profile } \\
\text { - Program internasional } \\
\text { Price: } \\
\text { - Biaya pendaftaran } \\
\text { - DP3 } \\
\text { - USP } \\
\text { - SPP } \\
\text { - Uang seragam } \\
\text { Place: } \\
\text { Lokasi strategis karena berada dalam kawasan universitas } \\
\text { Kristen satya Wacana yang posisinya diketahui oleh } \\
\text { masyarakat luas } \\
\text { Promotion: } \\
\text { - Brosur } \\
\text { - Website sekolah } \\
\text { - Tim promosi } \\
\text { - Tutor sebaya (Prospek senior-junior) } \\
\text { Physical evidence: } \\
\text { - Laboratorium (biologi, fisika, dan kimia) } \\
\text { - Lab komputer } \\
\text { - Ruang kelas } \\
\text { - Ruang kepala sekolah } \\
\text { - Ruang guru }\end{array}$ \\
\hline
\end{tabular}




\begin{tabular}{|c|c|c|}
\hline & & $\begin{array}{l}\text { - Ruang tenaga administrasi } \\
\text { - Ruang BK } \\
\text { - Ruang OSIS } \\
\text { - Gedung olah raga } \\
\text { - Cafetaria } \\
\text { - Teater } \\
\text { - Perpustakaan } \\
\text { - UKS (putra/putri) } \\
\text { - Toilet } \\
\text { - Atm } \\
\text { - Klinik } \\
\text { - Dll } \\
\text { People (SDM): } \\
\text { - Guru } \\
\text { - Pegawai administrasi } \\
\text { - Komite sekolah } \\
\text { - Petugas kebersihan } \\
\text { - Petugas keamanan } \\
\text { Process: } \\
\text { - Sistem moving class } \\
\text { - Penjurusan sejak kelas X } \\
\text { - Program reinforcement } \\
\text { - Kegiatan wisuda bagi lulusan kelas XII }\end{array}$ \\
\hline 3 & Cooperative strategic & $\begin{array}{l}\text { - Membangun kemitraan dengan SMP-SMP yang } \\
\text { mempunyai antusian tinggi terhadap SMA Lab } \\
\text { - Kerjasama dengan negara lain seperti Korea, Australia } \\
\text { dan Jepang untuk pertukaran pelajar setiap tahun } \\
\text { - Membangun kemitraan dengan instansi lain terkait } \\
\text { pengembangan kualitas pendidikan di SMA Lab }\end{array}$ \\
\hline
\end{tabular}

\section{Lampiran 2}

Tabel Jenjang Pendidikan Guru SMA Kristen Satya Wacana

\begin{tabular}{|c|c|c|c|c|}
\hline \multirow{2}{*}{$\begin{array}{c}\text { Tingkat } \\
\text { Pendidikan }\end{array}$} & \multicolumn{3}{|c|}{ Status } & \multirow{2}{*}{ Jumlah } \\
\cline { 2 - 4 } & Guru tetap/PNS & Kontrak & GTT & \\
\hline SLTA & - & - & 1 & 1 \\
\hline D3 & - & - & 1 & 1 \\
\hline S1 & 14 & 4 & 9 & 27 \\
\hline S2 & 3 & 2 & 2 & 7 \\
\hline \multicolumn{3}{|r}{ Total } \\
\hline
\end{tabular}

Sumber: Data Sekolah (2016)

Tabel Data pegawai non guru SMA Kristen Satya Wacana 
Pengembangan Model Strategi Bersaing Berbasis The New 7-s's Sekolah Menengah Atas Swasta di Kota Salatiga | Lowisye Leatomu \& Bambang Ismanto

\begin{tabular}{|c|c|c|c|c|}
\hline \multirow{2}{*}{$\begin{array}{c}\text { Tingkat } \\
\text { Pendidikan }\end{array}$} & \multicolumn{2}{|c|}{ Status } & \multicolumn{2}{c|}{ Jenis Kelamin } \\
\cline { 2 - 5 } & Tetap & Kontrak & L & P \\
\hline D3 & 1 & - & - & 1 \\
\hline SMA & 10 & 1 & 8 & 3 \\
\hline SMP & 1 & - & 1 & - \\
\hline SD & - & 1 & 1 & - \\
\hline
\end{tabular}

Sumber: Data Sekolah (2016) 


\section{Lampiran 3}

Gambar. 4.2. Struktur organisasi SMA Kristen Satya Wacana

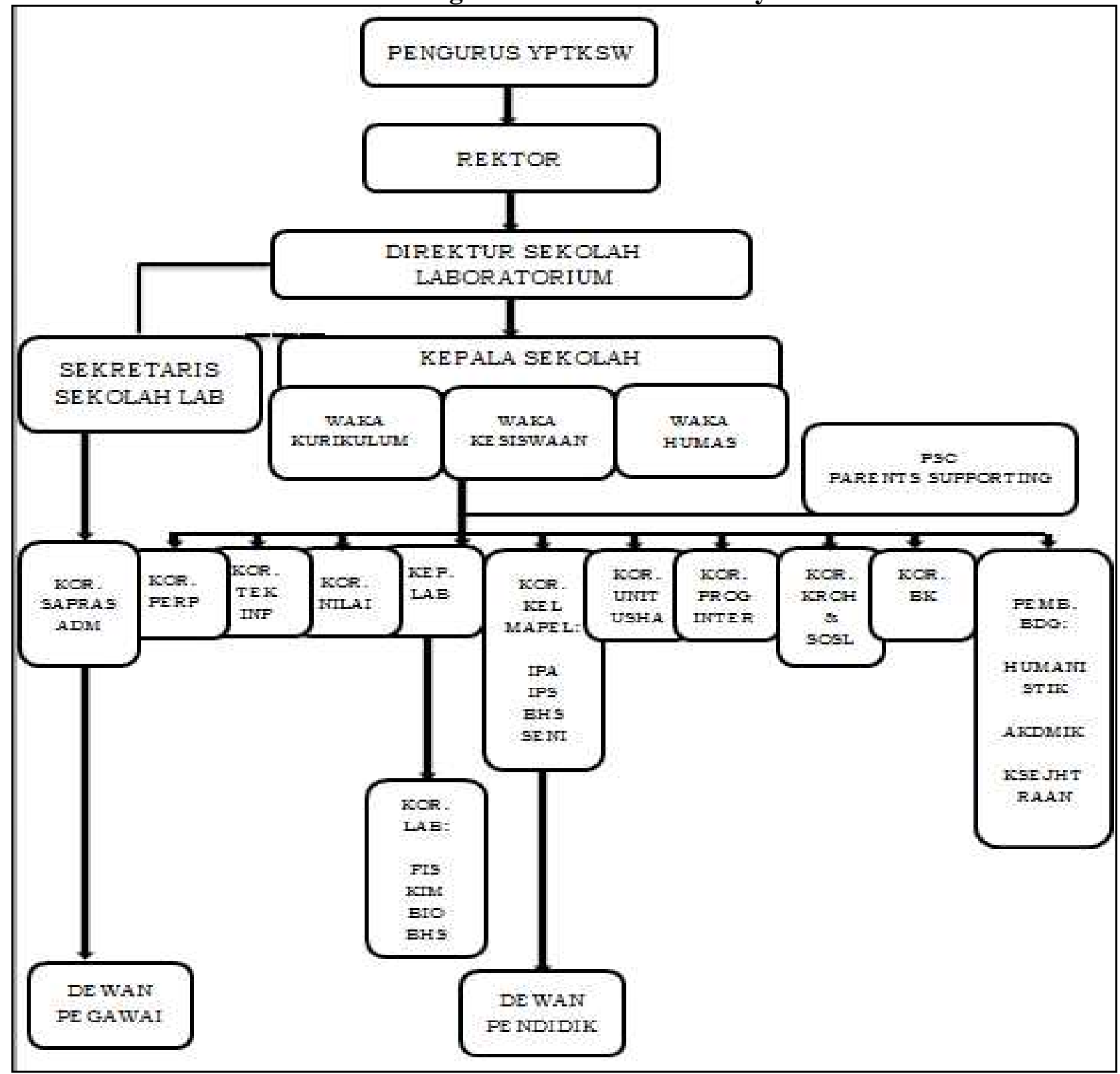

